\title{
Natural Products Potential and Scope for Modern Cancer Research
}

\author{
Rajeev Nema $^{1,2 *}$, Sarita Khare ${ }^{1}$, Parul Jain ${ }^{3}$, Alka Pradhan ${ }^{4}$, Abhishek Gupta ${ }^{2}$, Dharmendra Singh ${ }^{2,4}$ \\ ${ }^{1}$ Sarojini Naidu Government Girls Post Graduate (Autonomous) College, Bhopal, India; ${ }^{2}$ Center for Microbiology \& Bio-Technology \\ Research and Training, Institute Bhopal, Bhopal, India; ${ }^{3}$ S.V. Polytechnic College, Bhopal, India; ${ }^{4}$ Government of Motilal Vigyan \\ Mahavidyalaya, Bhopal, India. \\ Email: "rrsht.nema@gmail.com, ${ }^{*}$ rajeevnema07@gmail.com
}

Received March $14^{\text {th }}, 2013$; revised April 15 ${ }^{\text {th }}, 2013$; accepted May $1^{\text {st }}, 2013$

Copyright (C) 2013 Rajeev Nema et al. This is an open access article distributed under the Creative Commons Attribution License, which permits unrestricted use, distribution, and reproduction in any medium, provided the original work is properly cited.

\begin{abstract}
In the present time Natural products are considered to be symbols of protection in comparison to the synthetic product that are regarded as unsafe to human life and environment. Although a large number of synthetic drugs are being added to the world of present pharmacopoeia, but still no system of medicine in the world has been able to solve all the health problems, which include diseases like Cancer. Therefore the search for innovative therapeutic constituents from plants is genuine and urgent. In India, there is an ocean of knowledge about medicinal plants and rich medicinal flora, but still only a few pearls have been searched as therapeutic agents. There are large numbers of original plants left which have not been investigated thoroughly from modern scientific view or their healing values have not been known. Thus there is an insistent need for systematic phytochemical examination of those plants which have not been investigated scientifically. More research can be done to investigate the unknown and unexplored potential of plants. Further analysis of plants (active compounds) can be carried out by way of making use of different analytical methods such as HPTLC, HPLC, NMR and UV spectrophotometer analysis or computer based drug designing.
\end{abstract}

Keywords: Medicinal Plant; Natural Product; Cancer Biology

\section{Introduction}

The word "Cancer" was coined by a Greek physician Hippocrates (460 - 370 BC), who is furthermore well thought-of as the "Father of Medicine". Hippocrates used the terms "carcino" and "carcinoma" to describe non-ulcer forming and ulcer-forming tumors. Galen (130-200 AD), another Roman physician, used the word oncos' (Greek for swelling) to describe tumors. A mature human comprises about $10^{15}$ cells; scores of them divide and differentiate in order to renew organs and tissues, which require cell turnover [1]. However, if the cells do not stop dividing, they may show the way to cancer. Characteristically, cancer is an uncontrolled proliferation of cells which become structurally abnormal and possess the ability to detach them from a tumor and begin a new lump at a remote site within the host [2].

Almost all types of cancer lead to the progress of tumors, unusual clusters of cells. However, not all tumors

\footnotetext{
*Corresponding author.
}

are cancerous. Tumors that cannot invade nearest tissues or spread to other parts of the body are called benign tumors. With unusual exceptions, benign tumors do not cause serious diseases and are not life threatening. Malignant tumors are cancerous tumors. Malignant tumors can invade and destroy nearest tissues and organs, and spread to other parts of the body. This spread of cancer cells from one part of the body to an additional distant site is called metastasis. In short, malignant tumors are capable of attack and metastasis, but benign tumors do not have these capabilities.

In other words Cancer is a circumstance which arises while a cell starts disobeying the check mechanisms, which control the rate of cell proliferation and starts dividing in an uncontrolled manner. This leads to the formation of a neoplastic tumor, which is normally benign at this stage, but becomes malignant, when it starts metastasizing, i.e. starts spreading to other tissues. Cancer arises mainly due to two reasons: 1) Gain of function of a proto-oncogene, and it becomes oncogenic; 2) failure of the function of a tumor suppressor gene (Figure 1). 


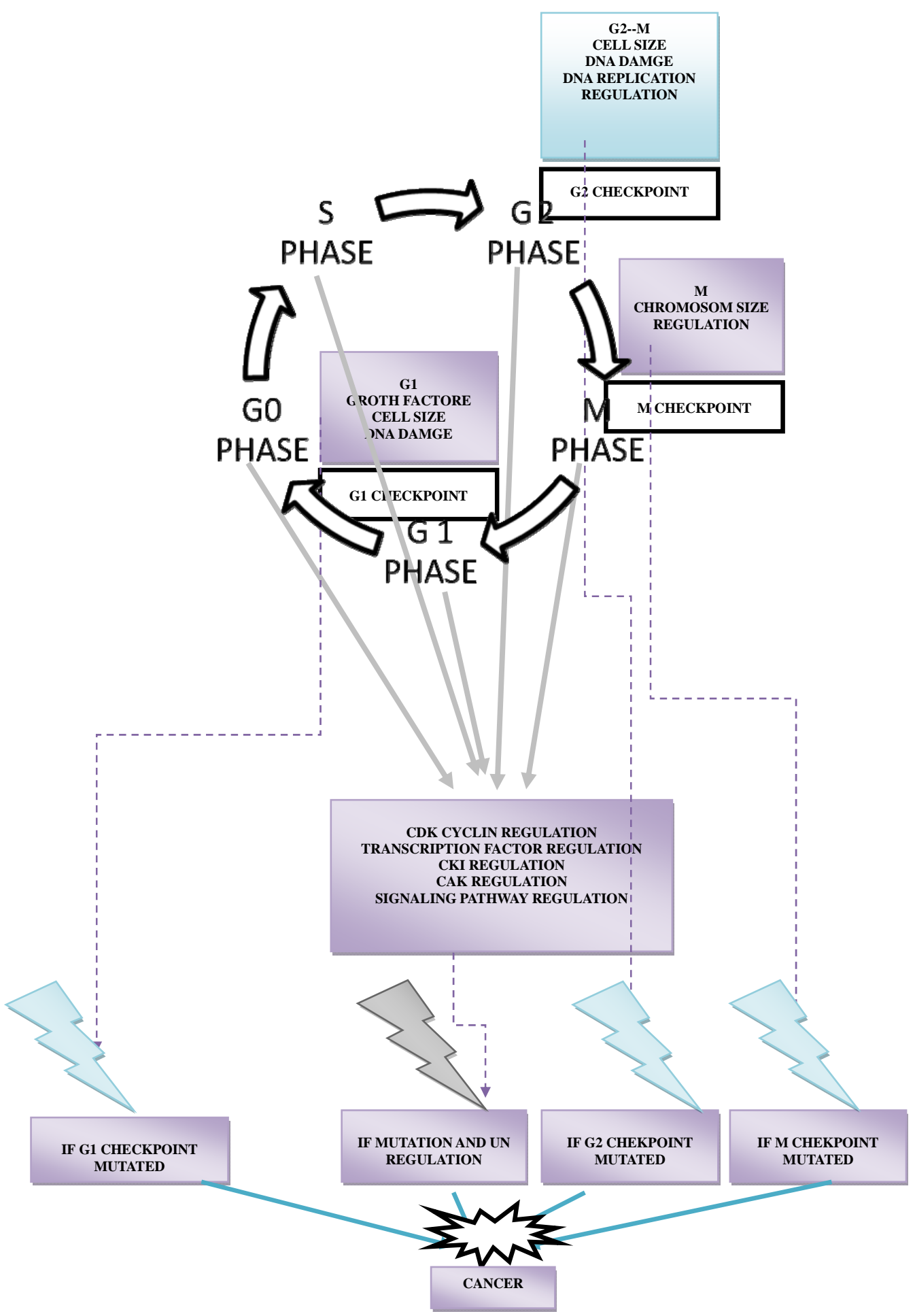

Figure 1. Cancer cell regulation and deregulation mechanism.

\section{Natural Products as an Alternative Treatment to Cancer Research}

\subsection{Natural Products with Anticancer Properties}

Natural products have potential source of chemical constituents with antitumor and cytotoxic activities owing to their enormous propensity, which synthesize a variety of structurally diverse bioactive compounds [3,4]. The rich and diverse plant sources of India are likely to provide effective anticancer agents. Medicinal plants can reduce or minimize the toxic side effect of chemotherapy and radiation treatment by reinforcing their cancer killing 
action, In addition medicinal plants have significant roles in the treatment of cancer and most new clinical applications of plant secondary metabolites and their derivatives have been applied towards fighting cancer. The National Cancer Institute collected about 35,000 plant samples from 20 countries and has screened approximately 114,000 extracts for anticancer action and Noteworthy Contributions have been made by Mathew and $[4,5]$. They worked out the cytotoxic activity of medicinal plants and studied their antiproliferative activity against cancer.

\subsection{Natural Products: Efficacy and Safety}

Natural products have anti-cancerous potential due to the occurrence of natural antioxidants carrying out as reduce- ing agents, free radical scavengers and quenchers of singlet oxygen. Greater part of their antioxidant action is due to bioactive compounds viz. flavones, isoflavones, flavonoids, anthocyanins, coumarins, lignans, catechins and isocatechins as well natural products can reduce or minimize the toxic side effect of chemotherapy and radiation treatment by reinforcing their cancer killing action. Significant assistance has been made by [6-12]. They worked out the cytotoxic activity of medicinal plants and studied their anti-proliferative activity against cancer. In the present time natural products are considered to be symbols of protection in comparison to the synthetic product that are regarded as unsafe to human life and environment that is by natural products had been priced for their medicinal importance (Figure 2).

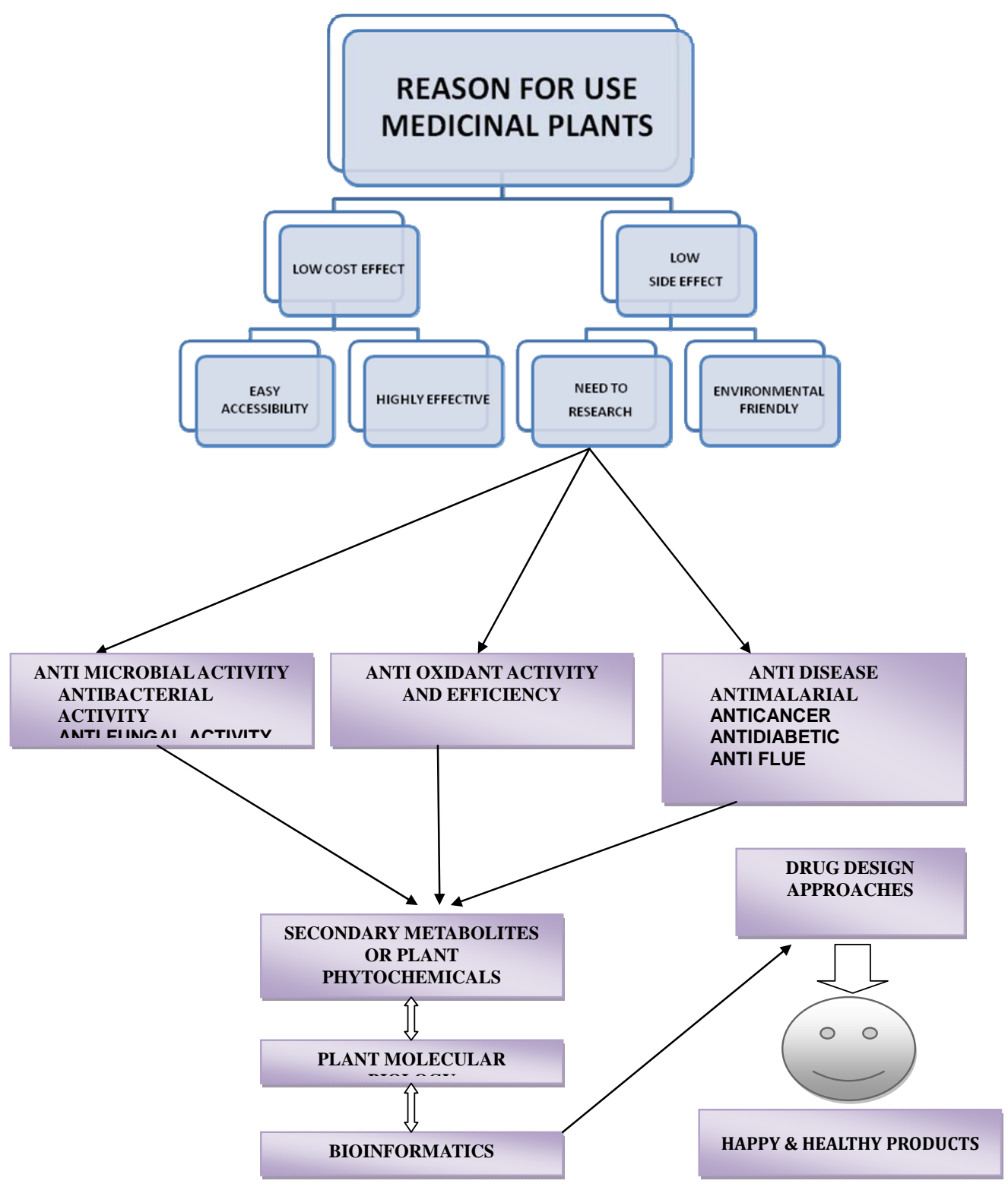

Figure 2. Medicinal plant use and prospects. 
Natural products are in great demand in the developing world for primary health care not only because they are inexpensive but also for better cultural acceptability, better compatibility with the human body and minimal side effects. This is primarily due to the general faith that natural products are relatively safe because they are natural [13]. In addition natural products are a potential source of chemical constituents with antitumor and cytotoxic activities owing to their enormous propensity, which synthesize a variety of structurally diverse bioactive compounds $[3,4]$. The rich and diverse plant sources of India are likely to provide effective anticancer agents.

\subsection{Natural Products Cancer Concept}

According to Charaka [14] and Sushruta [15] samhitas, two well-known Ayurvedic classics, cancer as in inflammatory or non-inflammatory swelling and mention them as either Granthi (minor neoplasm) or Arbuda (major neoplasm). Ayurvedic literature defines three body-control systems, viz., the nervous system (Vata or air), the venous system (Pitta or fire), and the arterial system (Kapha or water) which mutually coordinate to perform the normal functions of the body. In benign neoplasm (Vataja, Pittaja or Kaphaja) one or two of the three bodily systems are out of control and is not too harmful because the body is still trying to coordinate among these systems. Malignant tumours (Tridosaja) are very harmful because all the three major bodily systems lose mutual coordination and thus cannot prevent tissue damage, resulting in a deadly morbid condition [16].

\section{Neoplasm Classification According to Ayurvedia}

Group I: Diseases that can be named as clear malignnancy, which includes arbuda and granthi, e.g. mamsarbuda (melanoma) and raktarbuda (leukaemia), mukharbuda (oral cancer), etc.

Group II: Diseases that can be considered as cancer, such as incurable ulcers with e.g. tridosaj gulmas (abdominal tumours like carcinomas of the stomach and liver or lymphomas).

Group III: Diseases with the possibility of malignnancy, e.g. Visarpa (erysipelas), asadhya kamala (incurable jaundice) and nadi vrana (sinusitis) $[17,18]$.

\section{Free Radicals}

Free Radicals are molecules with an unpaired electron. Due to the presence of a free electron, these molecules are highly reactive. Free radicals can adversely alter lipids, proteins and DNA and have been implicated in aging and a number of human diseases. Lipids are highly prone to free radical damage resulting in lipid peroxidation that can lead to adverse alterations. Free radical damage to protein can result in loss of enzyme activity. Damage caused to DNA, can result in mutagenesis and carcinogenesis.

\subsection{Formation of Free Radicals}

In general, bonds don't split to leave a molecule with an odd, unpaired electron. But when weak bonds split, free radicals are produced. Free radicals are extraordinarily unstable and act in response quickly with other compounds, when the "attacked" molecule loses its electron; it becomes a free radical itself, start a chain reaction. All this happens within nanoseconds. Once the procedure is in progress, it can cascade, finally resulting in the trouble of a living cell (Figure 3).

\subsection{Free Radical-Targets}

Free radicals attack three main cellular components.

\subsubsection{Lipids}

Peroxidation of lipids in cell membranes is capable of damage cell membranes by disorderly fluidity along with permeability. Lipid peroxidation can also harmfully change the function of membrane bound proteins such as enzymes as well as receptors.

\subsubsection{Proteins}

Express damage to proteins is capable of caused by free radicals. This can influence numerous kinds of protein, interfering through enzyme goings-on and the utility of structural proteins.

\section{Free Radicals and Cancer}

Numerous research studies support the fact that many cancers, breast cancer in particular, are diet related. The development of cancer is composed of a series of complex processes of cellular and molecular changes. Active oxygen species and other free radicals have long been known to be mutagenic. There is also evidence that they act as mediators of the other phenotypic and genotypic changes that lead from mutation to neoplasia. Free radical production is universal in all respiring organisms and is enhanced by many disease processes, carcinogen exposure and under conditions of stress. Many chemical carcinogens are thought to act through the production of free radical metabolites or processes.

\section{Free Radicals and DNA Damage}

It is now widely held that the mutagenic capacity of free radicals is due to the direct Interaction of hydroxyl radicals $(\mathrm{OH})$ with DNA. Hydroxyl radicals have been detected by electron paramagnetic spectroscopy under conditions of active oxygen induced DNA damage. Hydrogen peroxide and superoxide do not directly interact with 


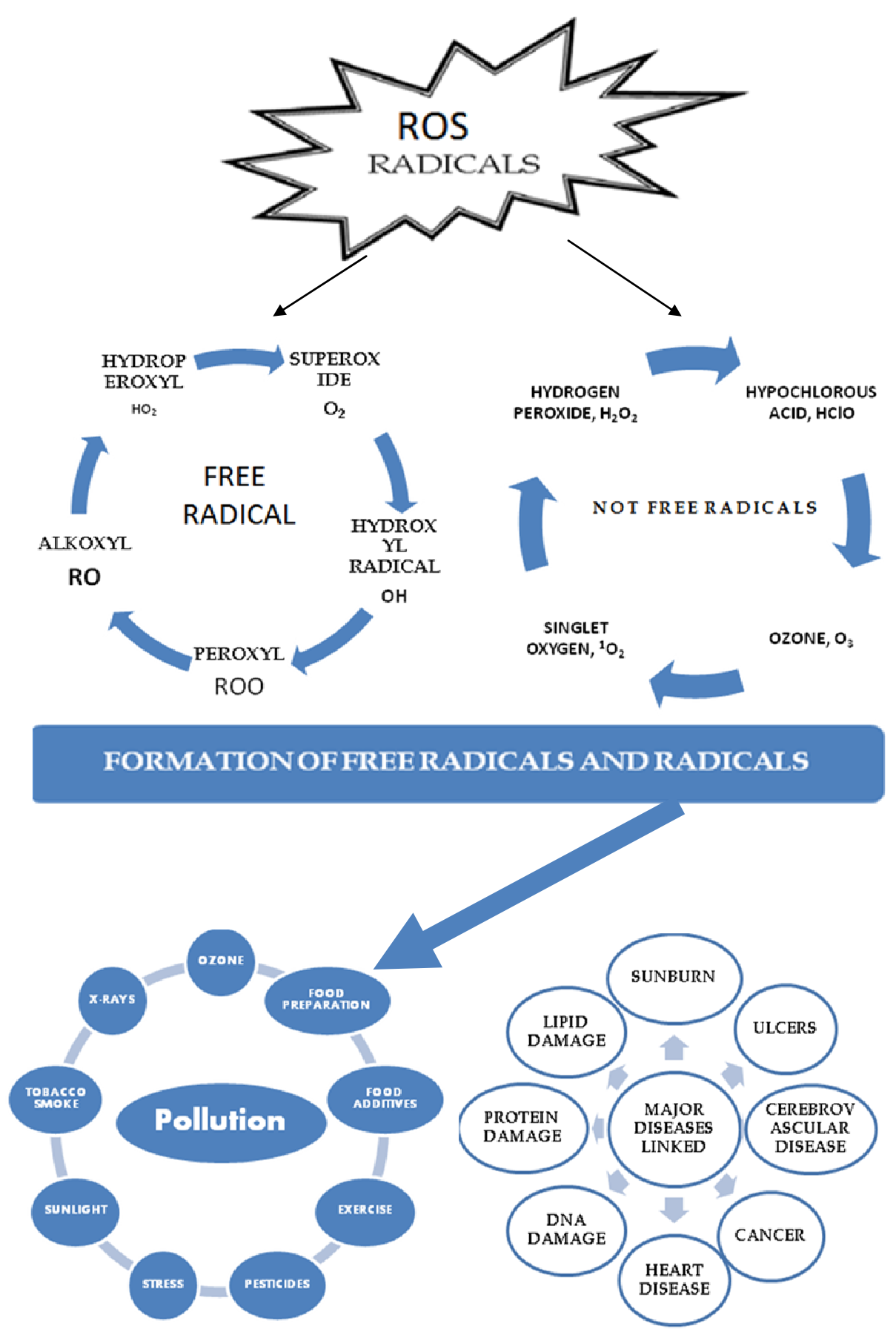

Figure 3. Free radicals (ROS) formation and function.

DNA to produce oxidative lesions in-vitro [19]. However, on interaction of these free radicals with transition metals the hydroxyl radical is produced which is responsible for DNA damage. Hence, the hydroxyl radical causes DNA damage by direct interaction in the generation of many of its genetic lesions. By selectively modifying gene expression in initiated cells, tumour promoters can obtain the production of clonally-derived benign growths. These tumours can be converted into rapidly growing malignant neoplasms through further DNA damage.

\section{Natural Products Drug Development and Discovery}

Medicinal, herbal medicines have a vital role in the prevention and treatment of cancer. Different efficient compounds resulting from natural products have been isolated as anticancer agents. These chemical compounds are formulated with a view to generate efficient drugs 
against cancer. Some of the direct molecules isolated from different medicinal plants are previously in use to treat cancer and chemotherapeutic side effects. These prospective and successful anticancer molecules contain Vincristine, Vinblastin, Taxol, Camptothecin, Podophyllotoxin, taxol, topotecan and irinotecan, flavopiridol, roscovitine, combretastatin A-4, betulinic acid and silvestrol are in clinical or preclinical improvement. There are more than 270,000 higher plants existing on this globe. But only a small portion has been explored phytochemically. So, it is anticipated that plants can provide potential bioactive compounds for the development of new 'leads' to cancer diseases. Several folk medicinal plants have been studied for anti cancer pharmacological activity in recent years. In this review we also explain and discuss numerous approaches to selecting higher plants as candidates for drug development with the greatest possibility of success. For the reason that of high death rate associated with cancer and because of serious side effects of chemotherapy and radiation therapy, many cancer patients search for alternative complementary methods of treatment (Figure 4).

Current review reveals the different potential applications of antioxidant/free radical manipulations in avoidance or control of disease. Natural products from dietary components such as Indian spices and medicinal plants are known to possess antioxidant activity. Recently more than 100 new active compounds have been isolated for clinical development, mostly as anti-cancer agents from plant source. Drug development is an essential part of research owing to low bioavailability of flavonoids which has been attributed to lack of stability, excessive metabolism, permeability problems, lack of site specificity in distribution, rapid elimination etc. The scope of the review is to assess and put into perspectives salient features of some of the recently reported work on dietary plants compounds including the methylated compounds

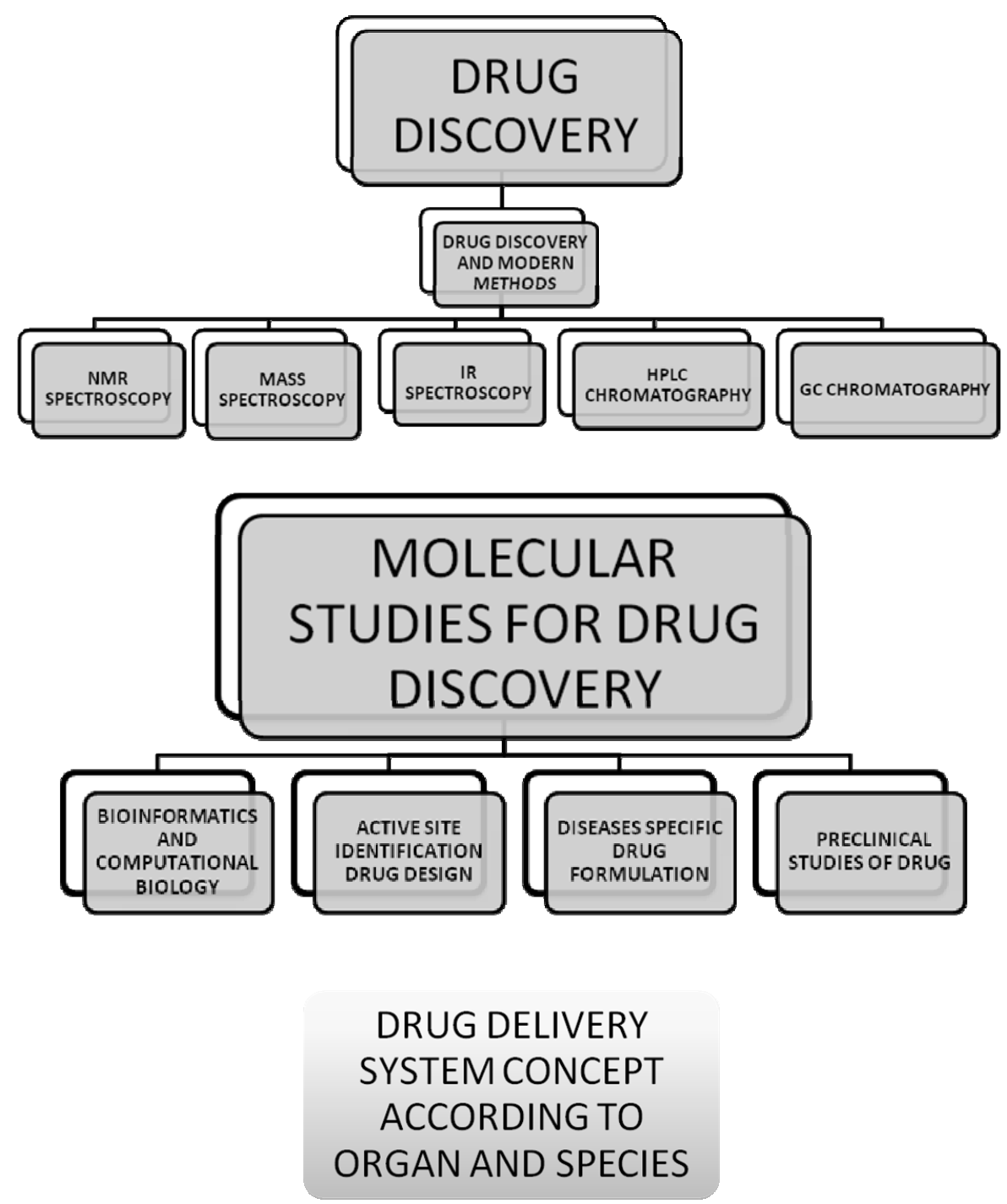

Figure 4. Drug discovery by molecular approach and chemical approach. 
that showed improved drug-like properties in context with the required features for the lead optimization program rendering a clinical candidate. Relevance of chemistry and biological techniques can surely create novel compounds that can be opportunely produced with the help of plants. Now days a number of approaches are being considered to selecting higher plants as reference for anti cancer drug development with the aim of drug accomplishment. With this we would be able to highlight the role of conventional medicine (ethno medicine) and its value for drug discovery. The goal of the present review paper is to determine whether the use of certain kind's neoplasm and warts are justified. If a scientific basis could be established the study would evaluate its constituents to determine which if any, would merit further study as potential new anticancer agents or leads to new anticancer compound.

\section{Conclusion}

This review covers the significant role of natural products used in therapy for various ailments, The data also indicated that natural product possess many pharmacological activities like anti ulcer, anti ageing, anti bacterial, anti oxidant, anti fungal, anti-inflammatory, anti diabetic, anti hepatotoxic, anti allergic anti cacer, anti tumor and vasodilator properties. In the current time, researcher creating innovative approaches like natural product, product chemistry, drug pharmacology approaches that would avoid cancer and their correlate genetics diseases. With the intention of so many researcher paved the way for identification and their genetically analysis, these advances technology for understanding of the genetics of different cancer. Now a day's emerging molecular technologies as well as drug designing approach, suggest that genetic defects of cancer cells could revolutionize and management of related disease. There are number of bioinformatics tools as well as online server for analysis predicts function and structural annotation. These program users friendly and give much aware results.

\section{Acknowledgements}

The authors express gratitude Prof. Dr. Usha Nair, Department of Chemistry Government, M.V.M. College Bhopal (M.P) India for her kind support.

\section{REFERENCES}

[1] J. S. Bertram, “The Molecular Biology of Cancer,” Molecular Aspects of Medicine, Vol. 21, No. 6, 2001, pp. 167-223. doi:10.1016/S0098-2997(00)00007-8

[2] National Cancer Institute, 2009. www.cancer.gov/

[3] M. A. Indap, S. Radhika, L. Motiwale and K. V. K. Rao, "Quercetin: Antitumor Activity and Pharmacological
Manifestations for Increased Therapeutic Gains,” Indian Journal of Pharmaceutical Sciences, Vol. 68, No. 4, 2006, pp. 465-469. doi:10.4103/0250-474X.27819

[4] J. B. Kim, H. N. Koo and H. J. Yoeng, "Introduction of Apoptosis by Korean Medicine Gagam-Whanglyun-Haedoktang through Activation of Capase-3 in Human Leukemia Cell Line, HL-60 Cells," Journal of Pharmacological Sciences, Vol. 97, No. 1, 2005, pp. 138-145. doi:10.1254/jphs.FPJ04021X

[5] P. J. Mathew and C. M. Unnithan, "Search for Plants Having Anti-Cancer Properties Used by the Tribals of Wayanad, Malappuram and Palakkad Districts of Kerala, India,” Aryavaidyan, Vol. 6, No. 1, 1992, pp. 61-67.

[6] S. Perumal and S. Ignacimuthu, "Screening of 34 Indian Medicinal Plants for Antibacterial Properties,” Journal of Ethnopharmacology, Vol. 62, No. 2, 1998, pp. 173-182. doi:10.1016/S0378-8741(98)00057-9

[7] C. Kirana, G. H. McIntosh, I. R. Record and G. P. Jones, "Antitumor Activity of Extract of Zingiber aromaticum and Its Bioactive Sesquiterpenoid Zerumbone,” Nutrition and Cancer, Vol. 45, No. 2, 2003, pp. 218-225. doi:10.1207/S15327914NC4502 12

[8] P. J. Ferguson, E. Kurowska, D. J. Freeman, A. F. Chambers and D. J. Koropatnick, “A Flavonoid Fraction from Cranberry Extract Inhibits Proliferation of Human Tumor Cell Lines,” Journal of Nutrition, Vol. 134, No. 6, 2004, pp. 1529-1535.

[9] G. M. Cragg and D. J. Newman, "Plant as a Source of Anticancer Agent,” Journal of Ethnopharmacology, Vol. 100, No. 1-2, 2005, pp. 72-79. doi:10.1016/j.jep.2005.05.011

[10] S. I. Kintzios, G. Marinopoulou, O. Moschopoulou, K. Mangana, K. Nomikou, K. Endo, I. Papanastasiou and A. Simonian, "Construction of a Novel, Multi-Analyte Biosensor System for Assaying Cell Division,” Biosensors and Bioelectronics, Vol. 21, No. 7, 2006, pp. 1365-1373. doi:10.1016/j.bios.2005.04.022

[11] A. A. Fali and M. Mocker, "Overview of Plant Drived Anticancer Drug," International Journal of Biomedical Sciences, Vol. 5, No. 1, 2009, pp. 1-11.

[12] H. T. Wamidh and M. M. Adel, "Antimicrobial, Cytotoxicity and Phytochemical Screening of Jordanian Plants Used in Traditional Medicine Molecules, Vol. 15, No. 3, 2010, pp. 1811-1824.

[13] W. M. Gesler, “Therapeutic Landscape: Medicinal Issue in Light of the New Cultural Geography," Social Science \& Medicine, Vol. 34, No. 7, 1992, pp. 735-746. doi:10.1016/0277-9536(92)90360-3

[14] W. Talib and A. Mahasneh, "Antiproliferative Activity of Plant Extracts Used against Cancer in Traditional Medicine,” Scientia Pharmaceutica, Vol. 78, No. 1, 2012, pp. 33-45. doi:10.3797/scipharm.0912-11

[15] P. V. Sharma and S. Charaka, "Choukhamba Orientalia, Vol. 5,” Choukhamba Bharti Academy, Varanasi, 1981.

[16] K. L. Bhishagratha and S. Sushruta, "Choukhamba Orientalia,” Choukhamba Bharti Academy, Varanasi, 1991, pp. iii-lxvi (I), i-xvii (II).

[17] G. C. Prasad, "Studies on Cancer in Ayurveda and Its 
Management,” Journal of Research in Science, Vol. 3, No. 4, 1987, pp. 147-167.

[18] R. M. Singh, “An Assessment of Ayurvedic Concept of Cancer and a New Paradigm of Anticancer Treatment in Ayurveda," Journaal of Cancer Medicine, Vol. 8, No. 5,
2002, pp. 609-694.

[19] L. H. Breimer, "Molecular Mechanisms of Oxygen Radical Carcinogenesis and Mutagenesis: The Role of DNA Base Damage,” Molecular Carcinogenesis, Vol. 3, No. 4, 1990, pp. 188-197. doi:10.1002/mc.2940030405 